\title{
Elaboration on Chinese Style Landscape Design Based on Taoist Thought and Culture
}

\section{- A Case of Some Residential Area}

\author{
Chaoyi You \\ School of Urban Planning and Architecture, Southwest Minzu University, Chengdu, China \\ Email: 651645399@qq.com
}

How to cite this paper: You, C.Y. (2019) Elaboration on Chinese Style Landscape Design Based on Taoist Thought and Culture. Open Journal of Social Sciences, 7, 115-125.

https://doi.org/10.4236/jss.2019.74010

Received: March 17, 2019

Accepted: April 13, 2019

Published: April 16, 2019

Copyright $\odot 2019$ by author(s) and Scientific Research Publishing Inc. This work is licensed under the Creative Commons Attribution International License (CC BY 4.0).

http://creativecommons.org/licenses/by/4.0/

\begin{abstract}
The long standing Chinese Taoism, whose philosophical thought of "heaven and earth co-exist in harmony, and united with everything" enriches all of the creations. Chinese traditional landscape, inheriting and profiting from excellent philosophical ideas, embodies the value of harmonious coexistence between human and nature, by the essence of "adapting to local conditions and leaning on the trend". The new Chinese style landscape, belonging to an evolution based on traditional design, lays great emphasis on spiritual connotation of "the union of heaven and human beings". Taking residential landscaping design project as an example, this paper analyses the expressive mode of Chinese style landscape design based on Taoist thought and culture, and aims to apply traditional artistic style into modern design and find the way to express landscape design.
\end{abstract}

\section{Keywords}

The Union of Heaven and Human Beings, Taoist Thought, Chinese Style Landscape, Modern Chinese Style

\section{Introduction}

Ever Zhuangzi said "human from the nature; heaven from the nature equally" [1], which means that the human beings originate from nature, and the universe also originates from nature. Similarly, Laozi said "For I am abstracted from the world, the world from nature, nature from the way, and the way from what is beneath abstraction" [2], which indicates the connection between human beings and nature, that is to achieve the harmony and unity between human beings and nature, we have to conform to the law of nature. All of the above contexts con- 
cerning of Chinese Taoist thought and culture focus on the "the union of heaven and human beings", which is to say the dependence and coexistence of human beings and nature. "The union of heaven and human beings", as the Chinese traditional thought and culture, is permeated into all of the creations, including the social life in various fields. The early Chinese landscape art, integrated with Taoist thought and culture, in the pursuit of the "artistic expression" with natural landscape, achieves the evolution of traditional Chinese style garden "landscape artistic" expression from the aesthetics of nature to the pursuit of artistic conception by its "originating from nature, integrating with nature".

Nowadays, in the vigorously developed era of information, science and technology, with the gradually mature of Chinese design, the modern Chinese style landscape design based on Taoist thought and culture is generated after experiencing thousands of years of history. And with its contemporary landscape design language, the modern Chinese style landscape design expresses the spiritual connotation in the context of traditional thought and culture by the combination of the modern aesthetics and the thought of "the union of heaven and human beings" in the Taoist ideological and cultural context perfectly, and creates the landscape design with traditional significance on the premise of satisfying modern functional needs and visual aesthetics, so that the artistic characteristics of Chinese Taoist thought and culture will be inherited and embodied in modern Chinese style landscape design.

Here with the reference of the concrete residential landscape design scheme, this paper starts with the analysis on the evolution from traditional Chinese style landscape to new modern Chinese style landscape, and then searches for the elements, implications and themes settings suitable for the "New Chinese Style" landscape design from the Taoist context of "Water benefits everything in the world but never contends its own contribution" and "The Greatest Virtue being Like water, Good for Everything", and by which to analyze the modern Chinese landscape design on "natural integration" and "spiritual connotation" embodied in the traditional Taoist cultural context, so that the "garden art" of traditional landscape will be elaborated and applied with the modern Chinese landscape design style.

\section{From Traditional Chinese Style Landscape to Modern Chinese Style "The Union of Heaven and Human Beings"}

\subsection{Evolution of Landscape Design from Traditional Chinese Style to Modern (New) Chinese Style}

1) In Tradition: Chinese Style Landscape

Chinese landscape, as an important carrier of Chinese traditional culture, is used to convey the comprehension and pursuit of beauty and nature. The basic design principle of traditional Chinese style landscape is to "reappear natural scenery" for the pursuing of the harmony and unity of human and nature, architecture and nature, even the whole creations and nature, which is different from the simplified application of nature in design, as a design expressing "ori- 
ginating from nature, superior than nature", it ingeniously integrates "artificial beauty" and "natural beauty" and creates landscape design with aesthetic value by the application of nature with respect. What we said the traditional significance of Chinese style landscape is for its appearance in early China and its priority at utilizing the beauty endowed by natural environment for "adapting to local conditions" and "leaning on the trend" in the old times. In the old era when there was no large-scale machinery, the Chinese style landscape is expressed in natural aesthetics by "manual finish, nature alike", eulogized so far. The Taoist thought of "heaven and earth co-exist in harmony, and united with everything" reveals the close relationship between human, heaven and earth, so we should live in harmony with nature in the process of recognizing, transforming and utilizing nature. The traditional landscape space need to be considered not only the satisfaction of human need, but also the relationship between heaven, earth and human, that is to say the harmony of human, architecture and environment [3]. And this spirit of "the union of heaven and human beings", as the highest realm pursued by garden art, perfectly embodied in Chinese style landscape design, which is inspired from the culture originating from nature and superior to nature permeated into all of the garden styles.

In this residential landscape design, it is the design expression of "reappeared natural style" from the traditional Chinese Taoist thought "originating from nature, integrating with nature". Regarding to the present residential landscape design, natural greening is greatly reduced due to the enhancing of land utilization rate. How can the natural landscape will be maximized in the design on the limited landscape land under the condition that the functional requirements are met in the era of "High Cost of Land". This scheme has carried out the deliberation and breakthrough in the road planning of the residential area to maximize the natural landscape by scheming the main road at the boundary of the residential area, reducing the interference to the internal space of the residential area, so as to meet the requirements of criteria and functions with the balance of natural landscape area. The subordinate road and garden path, as the auxiliary pathway, its scheme will maximized the natural landscape space, ensuring the area of natural landscape like hills and waters, and realizing the comprehension and realization for the pursuit of "human and nature co-exist in harmony" in the Taoist thought and culture (Figure 1).

2) In Modern: New Chinese Style Landscape Design

New Chinese style landscape design style, also named as the modernization of Chinese style landscape, which belongs to re-evolution based on the traditional Chinese style [4], keeping the essence of traditional Chinese style, and probing into the implication of the design, connotation and elements in the essence, combined with modern techniques and functional requirements, and endowed its design with modern aesthetic form in simplification by the expression of the spiritual connotation of traditional gardens in contemporary innovated landscape design language, to pursue the expression of artistic conception in specific landscaping techniques [5]. 


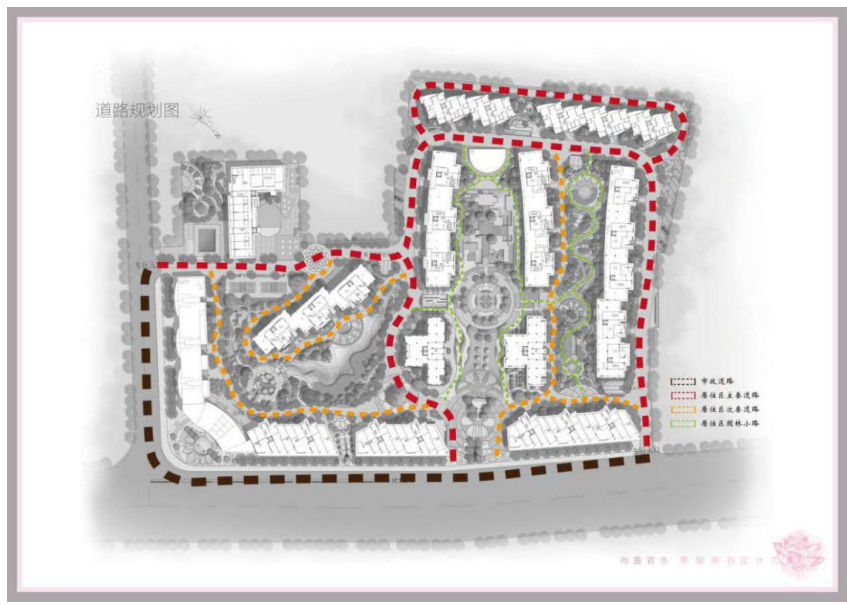

Figure 1. Road plan.

Modern Chinese style landscape design also embodies the harmonious beauty, advocating the harmony between human and nature, nature and architecture, movement and stillness, a spirit of "the union of heaven and human beings" [3]. Excelled at the natural scenery such as hills, rocks and lakes, it emphasizes the affinity between landscape and nature. Chinese style landscape lays stress on the nature and the natural beauty in the creation of layout and the allocation of buildings, landscapes and plants.

\subsection{Elaboration on Landscape Design "The Union of Heaven and Human Beings"}

This residential landscape design scheme, which learned from the cultural thought of traditional Chinese style landscape: the harmony and unity of human and nature. It emphasizes the affinity between residents and natural space, embodied on the enlargement of the area of natural landscape, the integration of the interior finishing in modern architecture and modern landscape design with nature to realize the basic principle of reappearing landscape and the spiritual connotation of "the union of heaven and human beings" in Chinese style landscape. In addition, it deliberates on the design implication, connotation and elements of Taoist ideological and cultural context, combining with modern functions and designers in a way of innovation, so as to achieve the integration of the traditional Chinese style landscape and modern new Chinese landscape design in modernization and pursue "the union of heaven and human beings" in the modern new Chinese style landscape (Figure 2).

\section{From the Taoist Thought "The Union of Heaven and Human Beings" to "Water Benefits Everything in the World but Never Contends Its Own Contribution"}

\subsection{The Implication of "Water Benefits Everything in the World but Never Contends Its Own Contribution" in Design}

Chinese Taoist thought is mainly embodied in traditional natural landscape garden 


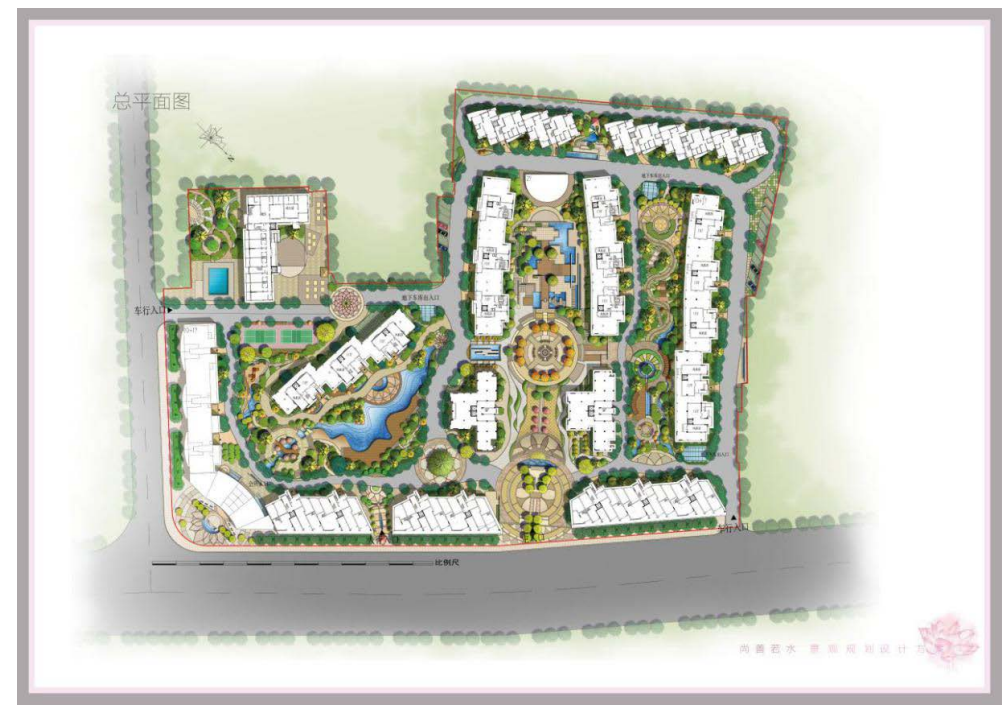

Figure 2. Landscape layout plan.

such as the water's meaning given by the most representative context "Water benefits everything in the world but never contends its own contribution" of Taoist thought is deeply embodied in the expression of traditional Chinese landscape, in which the "water" is not only one of the core elements of landscape, but also a symbol to express the implication for design. "Water benefits everything in the world but never contends its own contribution", it means that water moisturizes all of the creatures, yet with no scrambles, and the "water" in the Taoist ideological and cultural context contains the design implication integrating human and nature and the rich spiritual connotation in landscape expression. Generally, "water" as one of the main elements in the landscape design for residential space, it combines the interior finishing of landscape with the soft decoration to achieve the artistic space of "vividness in peacefulness". So the application of "water" in landscape engraves the design itself more deeply, since the element of "water" has profound implications and connotations in the context of Taoist thought and culture.

\subsection{The "Water" Element in Landscape Design}

This scheme applies the element of "water" into the design, integrating the "water", natural landscape and buildings together, and takes water-the main part of the overall landscape as the connecting medium of the overall landscape in the whole residential space, the reasons are as follows: firstly, water is the main element of nature, and the application of natural elements in landscape design, which is the important reflection of "the union of heaven and human beings", that is to say it integrates people's living environment with nature seamlessly, and penetrates the living environment with the natural "water" to realize the harmonious coexistence between human and nature (Figure 3); secondly, water is the dynamic design for landscape, which will inspire the overall dynamic and spatial vitality (Figure 4 \& Figure 5); thirdly, the meaning of "water" in the Taoist 


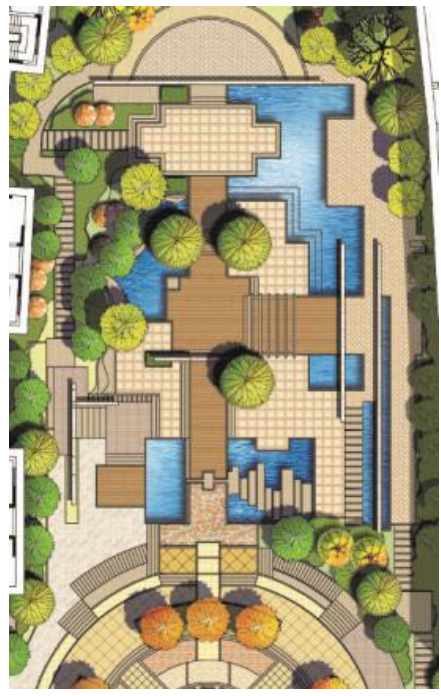

Figure 3. Partial landscape map.

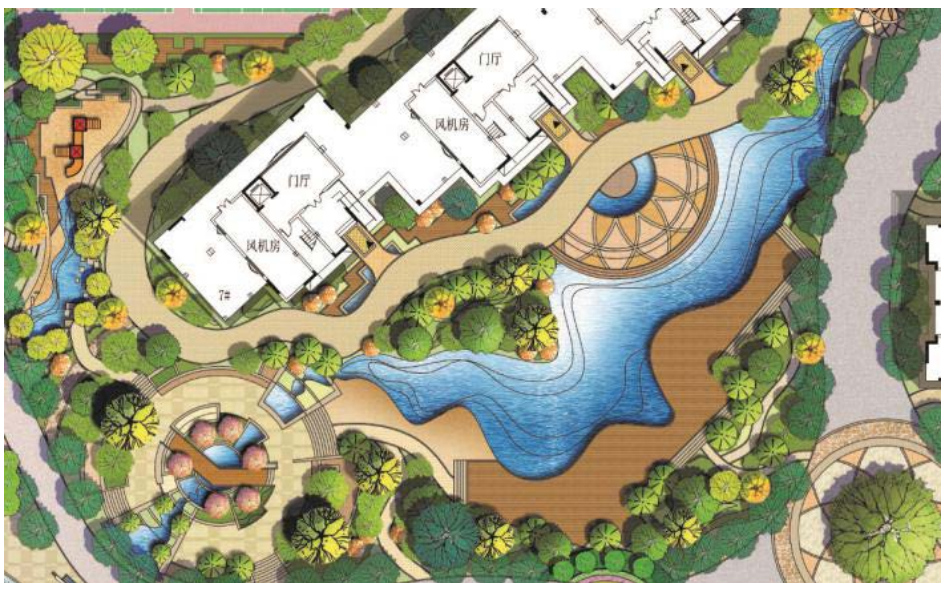

Figure 4. Partial landscape map.

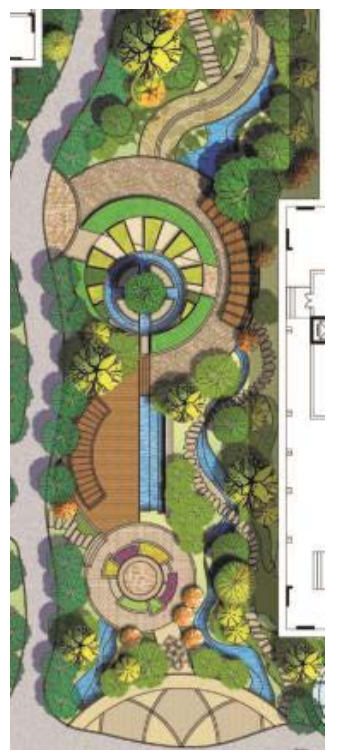

Figure 5. Partial landscape map. 
ideological and cultural context brings the whole landscape design with profound connotation and significance. In view of the above-mentioned facts about the significance of "water" in the expression of landscape design, water should be chosen as a connecting medium and the main elements for landscape design and application.

\section{The Higher Level Pursuit Rising from "Water Benefits Everything in the World but Never Contends Its Own Contribution" to "The Greatest Virtue being Like Water, Good for Everything"}

\section{1. "Greatest" Is the Living Quality in Pursuing the Environmental Design with "Nobility"}

\section{1) Design Environment}

The concept of landscape design in this residential area symbolizes the noble, the comfortable and the natural. In the context of Taoist thought and culture, "Greatest" means the artistic pursuit for the "Nobility" of living environment quality, the striving for the creation of noble and qualified life and environment. In the modern society, with the rising cost of housing, people pay more attention to the geographical location and future value of houses, but neglect the environment they lived inside. Giving another example, some children settle their parents in the city after their material conditions are improved. While they consider the convenience of the city only, but neglect the adaptability of living environment provided to the elderly. Based on these two points, this scheme will be designed to create an environmental space that is really suitable for people who enjoy life, and to enhance the improvement of landscape as the important segment, so that the present quality of life will get improved in their own environment, by which a high-quality landscape design space will be created to provide people with a more superior natural environment.

2) Design Expression

Taking the urban location of the residential area as the measurement of its value, the scheme itself breaks the conventional idea, with its value lies in the pursuit of the quality of life and the concept of integrating with nature, to create the living environment with "the union of heaven and human beings" and the life temperament with "The Greatest Virtue being Like water, Good for Everything", and help the people enjoy the comfort of life and nature outside the social pressure, get the improvement on life and environment. In addition this scheme will ease the old people who living away from hometown to help them better adapt to the natural atmosphere of modern life.

\section{2. "Virtue" Is the Element and Theme of the Design}

"Virtue" is a belief in life and an embodiment of the inner living pursuit. With the effect of this more and more competitive economic society, people need not only a pure land in his mind, but also a pure land in life, which will be realized 
by a suitable selection of "home". Then how to construct this kind of pure land, which will be deeply explored in this scheme design.

\subsubsection{Element of the Design}

1) Lotus. "For me, lotus is the only one for me, She grows up in the mud, but with no dirt on it, She is cleansed with water but shows no coquettishness" [6].

2) Bamboo. "Silver bamboo joint moisturized by the dew, Its green branches sway and sweep in gentle, With the refined appearance looks like a gentleman, No matter where it is planted, it always adapts" [7].

Both lotus and bamboo are the symbols of Chinese traditional culture. The poems describing them are all for the expression of their noble qualities, cleanliness and honesty. Here the characteristics of these two elements coincide with the design theme. Moreover, both lotus and bamboo are interdependent with "water"- the main element of this scheme, which embodies Taoist thought and culture, "originating from nature, superior than nature".

\subsubsection{Theme of the Design}

The design of the scheme is to create the artistic realm of "The Greatest Virtue being Like water, Good for Everything" by the application of "lotus" and "bamboo". In order to construct the pure land of "home", the theme of the design is embodied both in the design details and in the spiritual connotation by the elaboration of the internal quality and external performance of "lotus" and "bamboo".

"Lotus" is a common waterscape plant used in Chinese landscape theme, with its symbolic significance. The artistic conception inspired by the "lotus" will fully interpret some pure land and spiritual connotation pursued by people. The "lotus" elements have also been added into the design details, such as the rigid pavement. The waterfront square will be designed into a pattern of blooming lotus in water and kept forever (Figure 6).

The design idea of lotus will be realized in the form of pavement, so as to the design elements and themes will be demonstrated in different design forms (Figures 7-9).

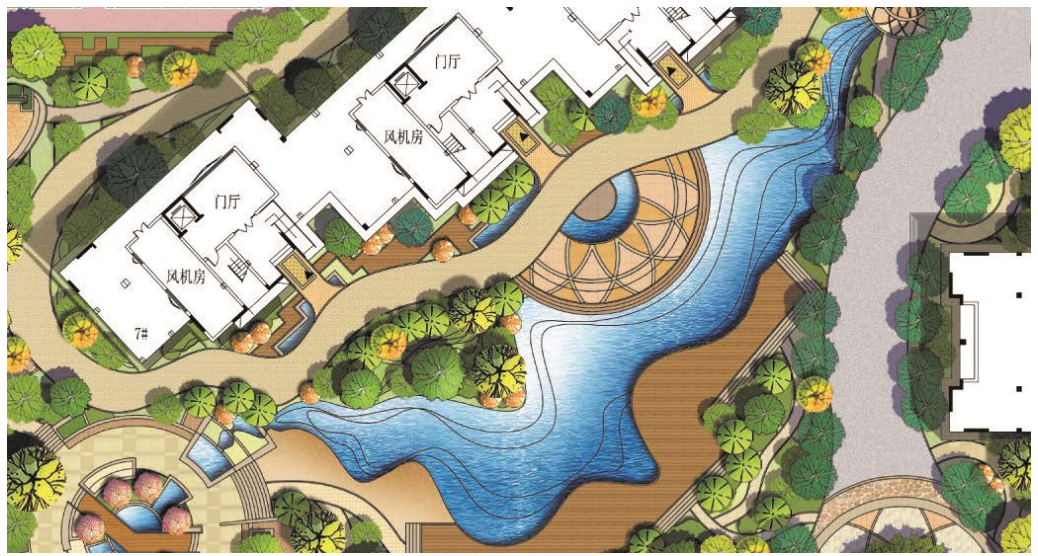

Figure 6. Partial landscape map. 


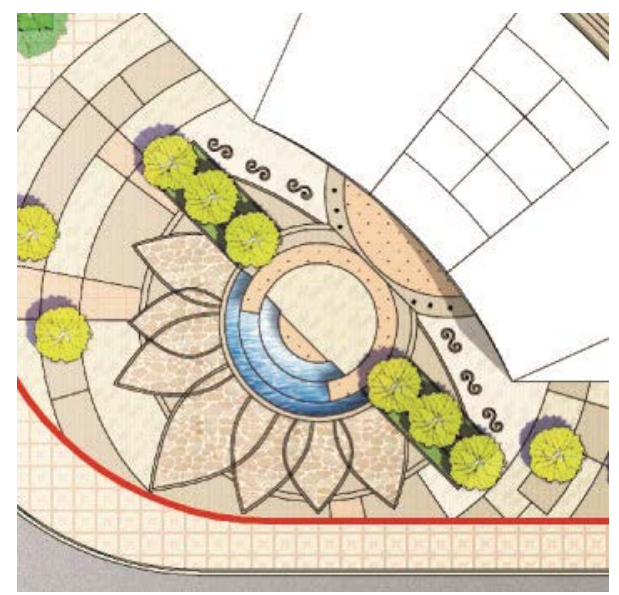

Figure 7. Partial landscape map.

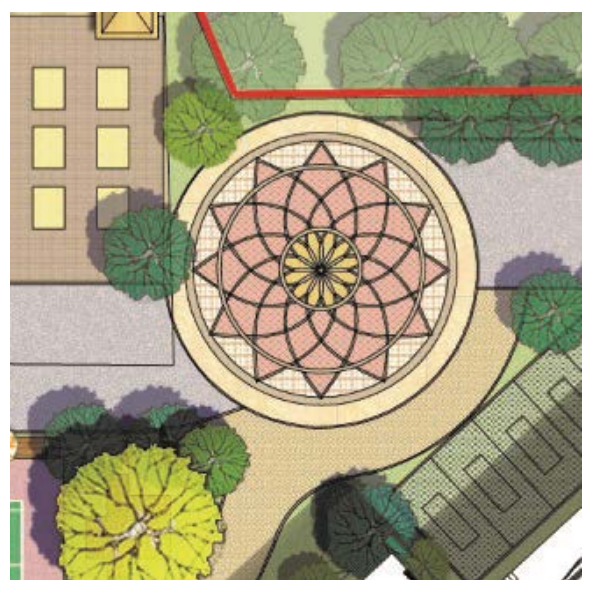

Figure 8. Partial landscape map.

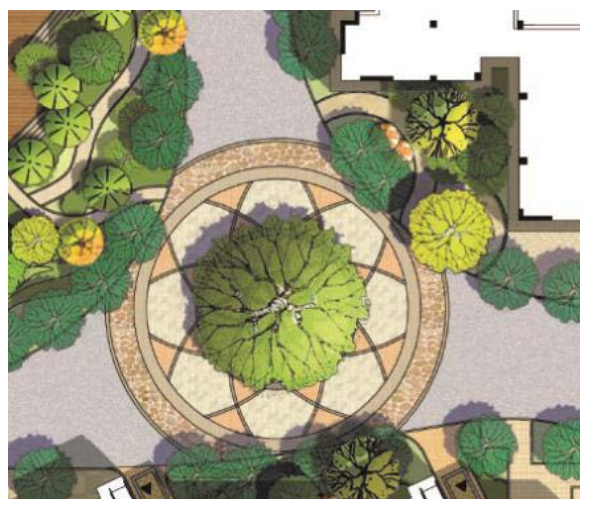

Figure 9. Partial landscape map.

For the design expression of "bamboo", which is mainly for the atmosphere creation. The large stretch of bamboo forests will be used to design a comfortable and quiet space environment.

\section{3. "Being Like" an Attitude-Let Nature Take Its Course}

The landscape design of this scheme always adheres to the thought of "con- 
forming to nature, integrating with nature", so does with the allocation of landscape plants. The allocation of plants is related to the climate and geographical location, so this scheme releases a new geographic positioning mode, fuzzy position with clear varied climate. It analyses the landscape vegetation allocation suitable for different climate conditions in the South and North respectively when the scheme is settled in the north and South with different environment, and by which the "being alike" artistic pursuit of this scheme is embodied as a kind of design forms adapted to the right time and places.

\section{4. "Water"-A Thought Integrating All Creatures}

We all know that water moisturizes all of the creatures with no scrambles. So the highest realm of virtue is like water, which elaborate the superior realm of "The Greatest Virtue being Like water, Good for Everything" in a flow state when acting, sometimes being quiet as stationary water, and other times with the tenacity of water, bending or stretching. It will definitely bring you an immersed sense in the living space of" The Greatest Virtue being Like water, Good for Everything " to construct the environmental quality including "quiet" and "resilient". As the main element of this scheme, "water" integrates the design concept, theme and artistic conception to create a residential landscape design in the context of Taoist thoughts.

\section{Termination}

With the blossoms of Chinese Taoist thoughts, "the union of heaven and human beings" points out the philosophical concept of harmony and unity between human and nature. The landscape design of this residential area learns the connotation and elements of design from the context of Taoist thought and culture, so that its design can meet the needs of modern functions and aesthetics, and endow design with certain design implications and connotations. One is to seek the reappearance and expression of nature from "harmony between man and nature the union of heaven and human beings" and to derive other ideological realms; the other is to seek the spiritual connotation of design elements and implications from "The Greatest Virtue being Like water, Good for Everything"; the third is to settle down the design theme and concept of its design scheme from "the union of heaven and human beings". By combining the above three points, we will design a new environmental space of Chinese-style landscape in the ideological and cultural context of Taoism.

In practice, "union of heaven and human beings" and natural elements are widely applied in traditional landscape design and modern landscape design, while in the development process of modern cities, such design concepts will hardly be applied into the real cases. For this reason, this paper expresses as much as possible the design representation of the "New Chinese Style" landscape design in practice with the form of design scheme with the intention to excavate more and more inspiration from traditional thoughts for innovation, and advo- 
cate the heritage of the design application of traditional thoughts. Considering the above assumptions, from the draft to the design, the scheme derives from the citation and reference of Chinese landscape to Taoist thought and culture, combines its essence with modern (new) Chinese landscape design and integrates the elements of the same style, to reflect the design theme and design concept of the scheme and express in different forms. The design of this scheme achieves both the residents and nature with the truly "union of heaven and human beings", and brings the residents the spiritual connotation of "Greatest" Virtue as water, so as to realize the improvement of self living quality.

\section{Acknowledgements}

This research was funded by National Natural Science Foundation of China [grant number: 51508484] and this project is funded by the graduate innovative scientific research project [grant number: CX2019SZ07] of southwest university for nationalities.

\section{Conflicts of Interest}

The author declares no conflicts of interest regarding the publication of this paper.

\section{References}

[1] Zhuangzi (Family name Zhuang. First name Zhou. Style name Zixiu) (369-286 BCE) Zhuangzi·Outer Chapters.Mountain Tree.

[2] Laozi (Family name Li. First name Er. Style name Dan) Tao Te Ching (Chapter 25). The Spring and Autumn Period (604BC-531BC).

[3] The Embodiment of Chinese Traditional Culture in Modern Landscape Design Li Nana-Sun Jing.Li Shanshan 2012, 6 Modern Landscape.

[4] Xu, K.L. (2012) Application of Modern Chinese Style in Landscape Design-A Case Study of Liangzhu Jade Culture Industrial Park in Hangzhou. Study on Urban Construction Theory, 14.

[5] Li, Q. (2017) New Chinese Landscape Design Based on Traditional Culture Symbol. West Leather, 39, 107+111.

[6] Zhou, D.Y. The Love of Lotus. Collected Works of Zhou Yuangong, Song Dynasty.

[7] Liu, Y.X. Bamboo. Tang Dynasty. 